\title{
Curative Radiotherapy in Elderly Patients With Muscle Invasive Bladder Cancer: The Prognostic Role of Sarcopenia
}

\author{
GIANLUCA FERINI $^{1}$, ALBERTO CACCIOLA ${ }^{2}$, SILVANA PARISI $^{3}$, SARA LILLO $^{2}$, LAURA MOLINO $^{2}$, \\ CONSUELO TAMBURELLA ${ }^{2}$, VALERIO DAVI ${ }^{2}$, ILENIA NAPOLI ${ }^{2}$, ANGELO PLATANIA ${ }^{4}$, NICOLA SETTINERI $^{4}$, \\ GIUSEPPE IATI $^{5}$, ANTONIO PONTORIERO ${ }^{5}$, STEFANO PERGOLIZZI ${ }^{2,5}$ and ANNA SANTACATERINA ${ }^{4}$ \\ ${ }^{1}$ REM Radioterapia srl, Catania, Italy; \\ ${ }^{2}$ Radiation Oncology Unit - Department of Biomedical, \\ Dental Science and Morphological and Functional Images, University of Messina, Messina, Italy; \\ ${ }^{3}$ Fondazione Istituto Oncologico del Mediterraneo, Catania, Italy; \\ ${ }^{4}$ Radiation Oncology Unit - Papardo Hospital, Messina, Italy; \\ ${ }^{5}$ Radiation Oncology Unit, A.O.U. "G. Martino", Messina, Italy
}

\begin{abstract}
Background/Aim: To evaluate the impact of sarcopenia in muscle invasive bladder cancer (MIBC) elderly patients submitted to curative radiotherapy. Patients and Methods: Patients received radiotherapy between 2013 and 2018, and the skeletal muscle index was calculated to classify them as sarcopenic or non-sarcopenic. Primary endpoints were overall survival (OS), cancer specific survival (CSS), 90-day mortality and toxicity. Results: A total of 28 patients with a median age of 85 years met our inclusion criteria and 8 of them were sarcopenic. With a median prescribed dose of 61 Gy and a median follow-up of 24.5 months, OS rates in the sarcopenic and non-sarcopenic groups were 100\% and $84.4 \%$ at 3 months, $57.1 \%$ and $56.6 \%$ at 12 months, $38.1 \%$ and $50.3 \%$ at 24 months and $38.1 \%$ and $33.5 \%$ at 48 months, respectively; the CSS rates were $100 \%$ and $94.1 \%$ at 3 months and $68.6 \%$ and $88.2 \%$ at 12, 24 and 48 months, respectively. The actuarial 90-day mortality rate was $17.9 \%$ for the whole cohort, and $20 \%$ and $12.5 \%$ for the nonsarcopenic and sarcopenic groups, respectively. The radioinduced toxicity was similar in both groups. Conclusion: Sarcopenia cannot be considered a negative prognostic factor for MIBC elderly patients treated with external beam radiotherapy. Irradiation is therefore a feasible and effective choice for these patients, especially if unfit for surgery.
\end{abstract}

This article is freely accessible online.

Correspondence to: Sara Lillo, MD, Radiation Oncology Unit Department of Biomedical, Dental Sciences and Morphological and Functional Images, University of Messina, Messina, Italy. Tel: +39 0902212931,e-mail: saralillo93@hotmail.it

Key Words: Radiotherapy, sarcopenia, bladder cancer, elderly.
In Italy, bladder carcinoma is the fourth most common cancer in males, with a lower incidence among women. Urothelial carcinoma mostly affects the elderly population that frequently has comorbidities and general performance decline (1).

Radical cystectomy currently represents the gold standard treatment in patients affected by muscle invasive bladder cancer (MIBC), with a five-year overall survival rate between $42 \%$ and $58 \%$ after surgery and a significant mortality risk within the first 90 days that reached $9 \%$ in the larger case series of patients $(2,3)$. Some factors like multiple age-related comorbidities and a poor perfomance status can have a negative impact on patients' ability to tolerate radical cystectomy (4), but also a suboptimal nutritional state can seriously put at risk the postoperative recovery even leading to death in some cases (5).

For a systematic assessment of comorbidities and perfomance status impact on the preoperative risk of radical cystectomy many indexes with poor reproducibility and therefore low reliability have been suggested (6), whereas regarding the nutritional state an objective evaluation can be made through general clinical assessment and some easily quantifiable measures of body composition. In this sense, the most used indexes are the body mass index, body surface area, appendicular skeletal muscle mass, total psoas area, psoas muscle volume, psoas muscle index and skeletal muscle index $(5,7-9)$.

Sarcopenia indicates the loss of muscle mass, and an exhaustive definition has been provided by the European Working Group on Sarcopenia in Older People (EWGSOP) (10). An excellent tool to evaluate sarcopenia is the skeletal muscle index (SMI), introduced by Fearon et al. and calculated on axial computed tomography (CT) images thus being poorly affected by the inter-operator variability 
(11). It has been shown that sarcopenia is a negative prognostic factor both for the overall survival (OS) and cancer specific survival (CSS) of patients affected by melanoma, and breast, pancreas, colorectal, hepatobiliary and small cell lung cancer (12-16). Furthermore, some authors have recently reported that sarcopenia significantly increases both overall and cancer-specific mortality rates in MIBC patients submitted to radical cystectomy $(8,17-$ $19)$, thus paving the way to a wide spread of non-invasive treatments.

In this scenario, radiotherapy (RT) as part of a bi/trimodal approach including the transurethral resection of the bladder (TURB) with or without chemotherapy represents a valid alternative for all patients who refuse or are not suitable for surgical treatment due to comorbidities or unresectable tumor, as confirmed in other clinical scenarios (20-22).

Since muscolar mass loss is frequently correlated with age, the main purpose of the present study was to evaluate sarcopenic status in a cohort of elderly MIBC irradiated patients and to estimate its impact on treatment-related toxicity, 90-day mortality, OS and CSS.

\section{Patients and Methods}

Criteria for inclusion. All patients gave a written informed consent to the use of their anonymized clinical and image data for research and training purposes prior to treatment. The study was conducted in accordance with the general principles of "The Code of Ethics of the World Medical Association (Declaration of Helsinki)". Data related to MIBC patients irradiated between April 2013 and August 2018 were retrospectively collected by searching in the database of the Radiation Oncology Units of "Policlinico Universitario G. Martino" and "Azienda Ospedaliera Papardo" of Messina. Only patients $\geq 70$ years, unfit for surgical treatment or having refused it, with a MIBC TNM staging T $\geq 2 \mathrm{~N} 0 \mathrm{M} 0$ and eligible for RT were recruited.

Imaging, clinical and sarcopenia assessment. To perform each patient's muscular assessment, a single axial slice at the level of the body of L3 vertebra was extracted from the RT planning CT. The muscle area, expressed in $\mathrm{cm}^{2}$ and comprised the psoas, paraspinal muscles, transverse muscles, exterior and inner obliques, and rectus of the abdomen, was computed (Figure 1) and divided by the square of the body height expressed in meters to calculate the SMI.

In detail, the analysis of L3-slice body composition was carried out assuming specific thresholds of Hounsfield Unit (HU) for the different represented tissues. The reference range was between -29 and $150 \mathrm{HU}$ for the skeletal muscle (Figure 1C) and between -30 a -190 HU for the adipose tissue (Figure 1B), whereas the muscular area was finally calculated by automatically adding the related pixels (Figure 1D, E) and, if necessary, manual adjustments were made by the operator. According to the international consensus of cancer cachexia by Fearon et al., an SMI $<55 \mathrm{~cm}^{2} / \mathrm{m}^{2}$ for men and $<39 \mathrm{~cm}^{2} / \mathrm{m}^{2}$ for women was highly indicative of sarcopenic status (11).

Finally, the Charlson Comorbidity Index (CCI) was calculated to estimate the impact of several coexisting comorbidities on patient's survival.
$R T$ and follow-up. Patients were irradiated within 4-6 weeks after a maximum TURB. CT simulation was performed with the patient placed in a supine position having an empty bladder and lower limbs immobilized through a specific immobilization system (kneefix). Volumes to be treated were defined as follows: the gross tumor volume (GTV) included the macroscopic tumor clearly visible on CT simulation and MRI imaging if available, the clinical target volume (CTV) included the whole bladder excluding the negative limph nodes, and the planning target volume (PTV) derived from a radial expansion of $1.5 \mathrm{~cm}$ of the CTV in order to overcome setup bias and consider physiological bladder position variation from one RT session to another. The minimum reference isodose to cover PTV was 95\%. Rectum, femoral heads and small bowel were defined as organs at risk, so that specific dose-volume constraints were fixed and a maximum of two constraints could be unrespected: rectum V50<50\%, V60 <33\%; femoral head V42 <50\%; small bowel V45 $<195 \mathrm{ml}$ and V35 $<230 \mathrm{ml}$ if the volume included both the whole peritoneal cavity and the intestinal loops, V15<120 ml with Dmax $<55.5$ Gy in case only the intestinal loops included.

RT was delivered with a 6-10 MV linear accelerator adopting different irradiation techniques including 3D-conformal RT (3DCRT), intensity modulated RT (IMRT) and volumetric modulated arc therapy (VMAT). A 50 Gy dose was delivered to the CTV with a dose of $60 \mathrm{~Gy}$, and in some cases slightly above, on GTV, through 2-Gy daily fractions and a weekly schedule (5 days/week). Set-up check was carried out through cone-beam CT or EPID.

All patients were provided with a supportive therapy during all the irradiation time, including intestinal probiotics and urinary antiseptics in addition to dietary advices.

Acute toxicities, evaluated according to the RTOG scale, were weekly registered during and after treatment contextually to the 3-, 6and every 4-month follow-up visits. Treatment response has been evaluated through CT and/or cystoscopy at 8 weeks after the end of RT.

Statistical analysis. The primary endpoints of the present study were: 1) OS, defined as the time interval between the start of the RT and the date of death or, for alive patients, of the last follow-up and evaluated at fixed time points of 3, 12, 24 and 48 months; 2) CSS, defined as the time interval between the start of the RT and the date of death due to cancer evaluated at fixed time intervals of 3, 12, 24 and 48 months; 3) 90-day mortality, defined as the death rate at 90 days after the start of RT relative to the total number of patients that underwent the treatment. These three outcomes were calculated using the Kaplan-Meier method and all the results were considered significant if $p$-value was lower than 0.05 .

\section{Results}

According to the selection criteria, we identified 28 MIBC patients with a median age of 85 years (range $=71-90$ years). One patient received pre-RT chemotherapy administered systemically and one patient received concomitant chemoradiotherapy. All patients were previously submitted to an as wide as possible TURB that provided a histological classification of the tumor which resulted in the diagnosis of urothelial carcinoma in $26 / 28$ cases and a squamous carcinoma in 2/28 cases; an infiltration beyond the detrusor muscle (T4) was detected in only one case. Comorbidity burden was assessed by the CCI obtaining a median score of 


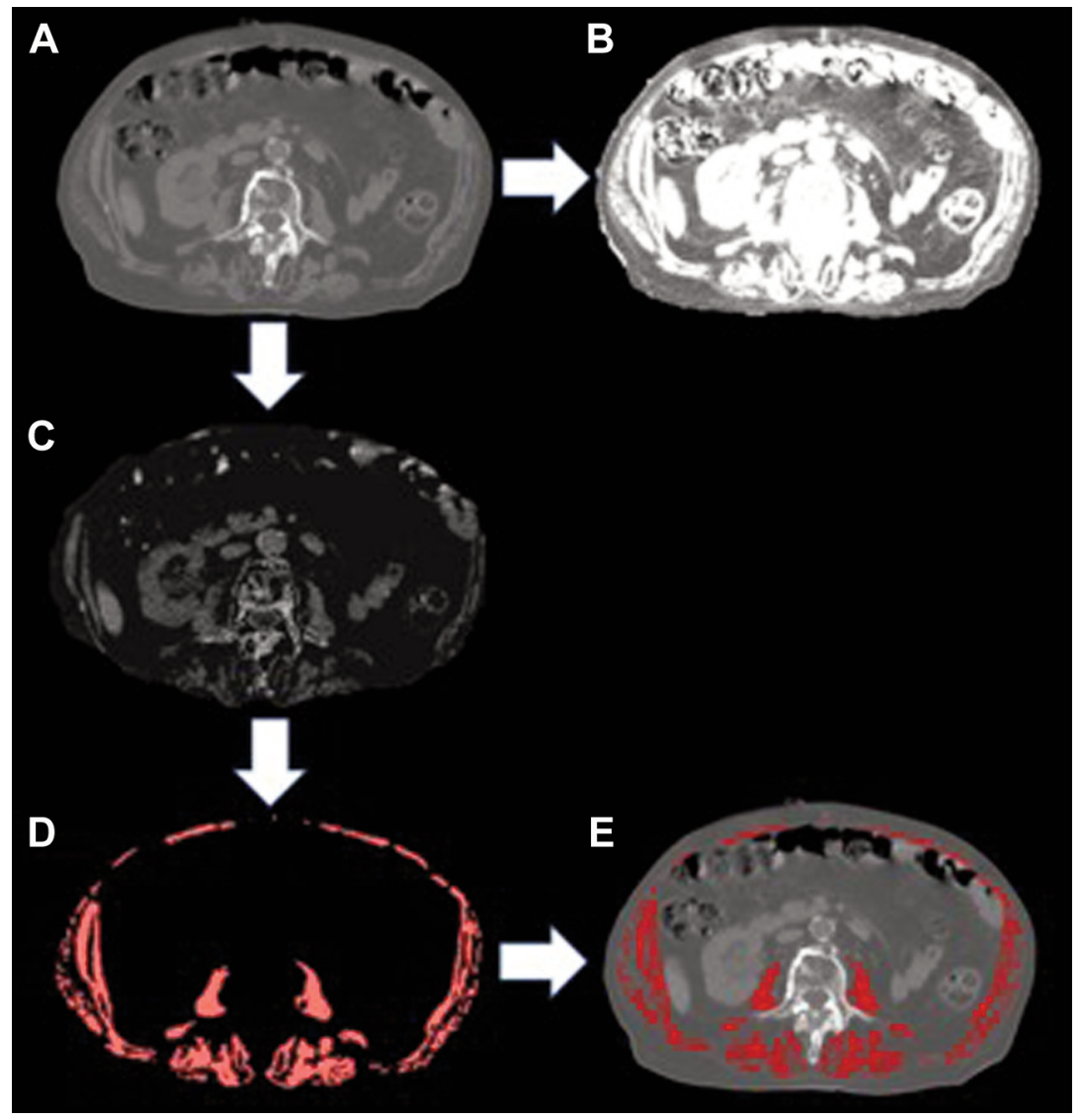

Figure 1. Workflow of the computation of the muscular area $\left(\mathrm{cm}^{2}\right)$. (A) CT slice passing through L3; (B) tissues with density between -30 and -190 HU corresponding to adipose tissue; (C) tissues with density between -29 and $150 \mathrm{HU}$ corresponding to skeletal muscle; (D) manually processed image to rule out non-muscular tissues; (E) final result.

8 (range=5-16). A complete list of the characteristics of the irradiated patients is provided in Table I.

The RT delivered was a 3D-CRT in $13 / 28$ patients, an IMRT in $14 / 28$ patients and a VMAT in $1 / 28$ patient. The total median dose was 61 Gy (range=29.1-69.6 Gy) achieved through an average daily dose of $210.9 \mathrm{cGy}$, and the median follow-up time was 24.5 months (range=3-64 months). Only in two cases dysuria was so severe to cause the interruption of the planned schedule. Median SMI was $72.4 \mathrm{~cm}^{2} / \mathrm{m}^{2}$ (range $=42.9-94.2 \mathrm{~cm}^{2} / \mathrm{m}^{2}$ ), and 8 of the 28 enrolled patients were sarcopenic.

At the last follow-up 14/28 patients had died, 13/28 were alive, and 1/28 was lost to follow-up. Median OS of the whole cohort was 12 months (range=3-60 months), and no substantial differences emerged comparing the median OS rates of the sarcopenic and the non-sarcopenic groups (15 vs. 42 months, respectively). For the whole sample, OS rates at $3,12,24$ and 48 months were $88.6 \%, 56.8 \%, 47.3 \%$ and $35.5 \%$ respectively, whereas for the aforementioned groups the OS rates at the same time intervals were $100 \%$ vs. $84.4 \%, 57.1 \%$ vs. $56.6 \%, 38.1 \%$ vs. $50.3 \%, 38.1 \%$ vs. $33.5 \%$, respectively (Figure 2). Only in 4 out of 13 dead patients, exitus was caused by cancer progression; of them, 2 were sarcopenic and 2 were non-sarcopenic. CSS rates at 3, 12, 24 and 48 months were $95.8 \%$ at the first interval of time and $82.9 \%$ at the remaining three. Comparing the sarcopenic and non-sarcopenic groups, the CSS rates were $100 \%$ vs. $94.1 \%$ at 3 months, and $68.6 \%$ vs. $88.2 \%$ at 12,24 and 48 months, respectively (Figure 2). Finally, the actuarial 90-day mortality rate was $17.9 \%$ for the whole sample, and $20 \% \mathrm{vs}$. $12.5 \%$ for the non-sarcopenic and sarcopenic groups respectively (Figure 2).

Regarding the radio-induced toxicities, among the 28 irradiated patients 14, 6, 6 and 2 experienced a G0/G1, G2, G3 and G4 toxicity, respectively, according to the RTOG scale (Table II). No significant differences were registered neither for frequency nor for severity between the sarcopenic and the non-sarcopenic patients, and only one of the two 
Table I. Patient and tumor characteristics.

\begin{tabular}{|c|c|c|c|c|c|c|c|c|c|c|c|c|c|}
\hline Patient & Gender & Age & Histology & Grading & TNM & CHT & $\begin{array}{c}\text { GTV } \\
\text { dose (Gy) }\end{array}$ & $\begin{array}{l}\text { Side } \\
\text { effects }\end{array}$ & $\begin{array}{l}\text { RTOG } \\
\text { score }\end{array}$ & Comorbidities & $\mathrm{CCI}$ & $\begin{array}{c}\mathrm{SMI} \\
\left(\mathrm{cm}^{2} / \mathrm{m}^{2}\right)\end{array}$ & Sarcopenic \\
\hline 1 & M & 83 & 0 & 2 & $\mathrm{~T} 2$ & / & 63 & 0,4 & 3 & 0 & 9 & 67.95 & No \\
\hline 2 & M & 87 & 0 & 2 & $\mathrm{~T} 4$ & l & 64 & 5 & 2 & $0,1,3,4$ & 8 & 70.13 & No \\
\hline 3 & M & 85 & 0 & 2 & $\mathrm{~T} 2$ & l & 60 & 0,8 & 1 & 0,4 & 8 & 54.55 & Yes \\
\hline 4 & M & 78 & 0 & 2 & $\mathrm{~T} 2$ & l & 69.6 & 6 & 1 & 5 & 6 & 84.82 & No \\
\hline 5 & M & 86 & 0 & 2 & $\mathrm{~T} 2$ & I & 60 & I & 1 & I & 6 & 54.86 & Yes \\
\hline 6 & M & 80 & 0 & 2 & $\mathrm{~T} 2$ & / & 60 & l & 1 & $0,6,7$ & 11 & 71.76 & No \\
\hline 7 & M & 89 & 1 & 3 & $\mathrm{~T} 2$ & / & 63 & 8 & 1 & l & 6 & 75.01 & No \\
\hline 8 & M & 76 & 0 & 3 & $\mathrm{~T} 2$ & l & 56 & 6,10 & 2 & 7 & 8 & 54.24 & Yes \\
\hline 9 & M & 85 & 0 & 3 & $\mathrm{~T} 2$ & I & 36 & 4,7 & 4 & $0,3,5,6,7$ & 16 & 76.71 & No \\
\hline 10 & $\mathrm{~F}$ & 87 & 0 & 2 & $\mathrm{~T} 2$ & I & 60 & 0,1 & 3 & 0 & 9 & 70.81 & No \\
\hline 11 & M & 81 & 0 & 2 & $\mathrm{~T} 2$ & I & 62 & 1 & 3 & 8 & 7 & 73.32 & No \\
\hline 12 & M & 86 & 0 & 3 & $\mathrm{~T} 2$ & I & 64 & $1,3,4$ & 3 & 0,1 & 10 & 67.69 & No \\
\hline 13 & M & 86 & 0 & 3 & $\mathrm{~T} 2$ & I & 60 & 8 & 1 & 0 & 8 & 94.15 & No \\
\hline 14 & M & 85 & 0 & 3 & $\mathrm{~T} 2$ & I & 64 & 6 & 2 & $1,4,5$ & 9 & 54.38 & Yes \\
\hline 15 & M & 81 & 0 & 3 & $\mathrm{~T} 2$ & I & 66 & 0,2 & 2 & 0 & 8 & 66.71 & No \\
\hline 16 & M & 71 & 0 & 3 & $\mathrm{~T} 2$ & I & 60 & 7 & 1 & 0 & 7 & 73.27 & No \\
\hline 17 & M & 90 & 0 & 3 & $\mathrm{~T} 2$ & I & 60 & I & 1 & 0,6 & 10 & 47.21 & Yes \\
\hline 18 & M & 89 & 0 & 3 & $\mathrm{~T} 2$ & I & 29.1 & 9 & 4 & / & 8 & 42.88 & Yes \\
\hline 19 & M & 87 & 0 & 3 & $\mathrm{~T} 2$ & I & 63 & 6,8 & 2 & 0,1 & 9 & 82.54 & No \\
\hline 20 & M & 85 & 0 & 3 & $\mathrm{~T} 2$ & I & 63 & I & $0 / 1$ & / & 5 & 54.97 & Yes \\
\hline 21 & $\mathrm{~F}$ & 83 & 0 & 3 & $\mathrm{~T} 2$ & I & 60 & 0 & 1 & l & 9 & 74.58 & No \\
\hline 22 & M & 89 & 1 & 3 & $\mathrm{~T} 2$ & l & 63 & I & $0 / 1$ & 0,4 & 9 & 74.71 & No \\
\hline 23 & M & 81 & 0 & 3 & $\mathrm{~T} 2$ & I & 64 & l & 1 & 0,2 & 8 & 80.44 & No \\
\hline 24 & M & 86 & 0 & 3 & $\mathrm{~T} 2$ & l & 60 & 7 & 1 & 0,5 & 9 & 88.60 & No \\
\hline 25 & M & 78 & 0 & 3 & $\mathrm{~T} 2$ & I & 66 & 0,6 & 2 & 0,1 & 9 & 89.40 & No \\
\hline 26 & M & 83 & 0 & 2 & $\mathrm{~T} 2$ & I & 60 & I & $0 / 1$ & 0 & 8 & 72.96 & No \\
\hline 27 & $\mathrm{~F}$ & 75 & 0 & 3 & $\mathrm{~T} 2$ & $\begin{array}{c}\text { Concomitant } \\
\text { carboplatin }\end{array}$ & 66 & 0 & 3 & 0 & 6 & 80.57 & No \\
\hline 28 & M & 90 & 0 & 3 & $\mathrm{~T} 2$ & Gemcitabine & 60 & 0,1 & 3 & 2,5 & 11 & 50.90 & Yes \\
\hline
\end{tabular}

Histology: 0 urothelial carcinoma, 1 squamous carcinoma; Side effects: 0 cystitis, 1 haematuria, 2 incontinence, 3 pollakiuria, 4 pelvic pain, 5 proctitis, 6 diarrhea, 7 strangury, 8 dysuria, 9 anuria, 10 skyn erythema; Comorbidities: 0 cardiovascular diseases, 1 metabolic disease, 2 glaucoma, 3 anaemia, 4 prostatic disease, 5 gastroinstestinal diseases, 6 BPCO, 7 renal diseases, 8 anaemia; CHT: chemotherapy; CCI: Charlson Comorbidity Index; SMI: Skeletal Muscle Index.

individuals that developed the G4 toxicity, causing RT interruption at the $14^{\text {th }}$ out of the $28^{\text {th }}$ and the $18^{\text {th }}$ out of the $30^{\text {th }}$ planned sessions, was defined as sarcopenic.

According to the experienced toxicity, patients can be classified in two groups (Table III); the first one (20 patients, 6 of which sarcopenic) exhibited minor to moderate gravity (G0/G1/G2) of the adverse events, and the second one ( 8 patients, 2 of which sarcopenic) showed a more severe treatment-related symptomatology (G3/G4). Examining the non-sarcopenic cohort, no increase in the frequency of G3-G4 toxicity versus G1-G2 toxicity was observed (6 vs. 14, respectively, with $30 \%$ of G3-G4 among the non-sarcopenic patients); comparable results were obtained conducting the same analysis in the sarcopenic group (2vs. 6, respectively, with $25 \%$ of G3G4 among the sarcopenic patients), confirming the lack of correlation of sarcopenia with a greater tendency to give RT-related side effects.
Patients' age did not significantly affect OS of our sample, as emerged by the lack of statistical correlation between them. The median CCI score of the whole sample was 8 (range=5-16), and comparing the OS of patients with a score higher and lower than this median value no significant differences were obtained regarding the 3-month OS $(83.3 \%$ vs. $92.9 \%$, respectively) and the 12 -month OS $(58.3 \%$ vs. $55 \%$, respectively). Within the sarcopenic group, the number of patients with a CCI score $>8$ was not greater than the number of patients with a $<8$ score ( $3 v s .5)$, being equally distributed. However, the number of patients with a score higher than 8 among the non-sarcopenic group were the same as those with a score lower than 8 (10 vs. 10). No significant correlation was observed neither between CCI and OS nor between CCI and sarcopenia.

Finally, higher grade toxicities (G3-G4) were significantly more frequent among patients with a greater CCI score (pvalue $=0.03$ ). 
os

os
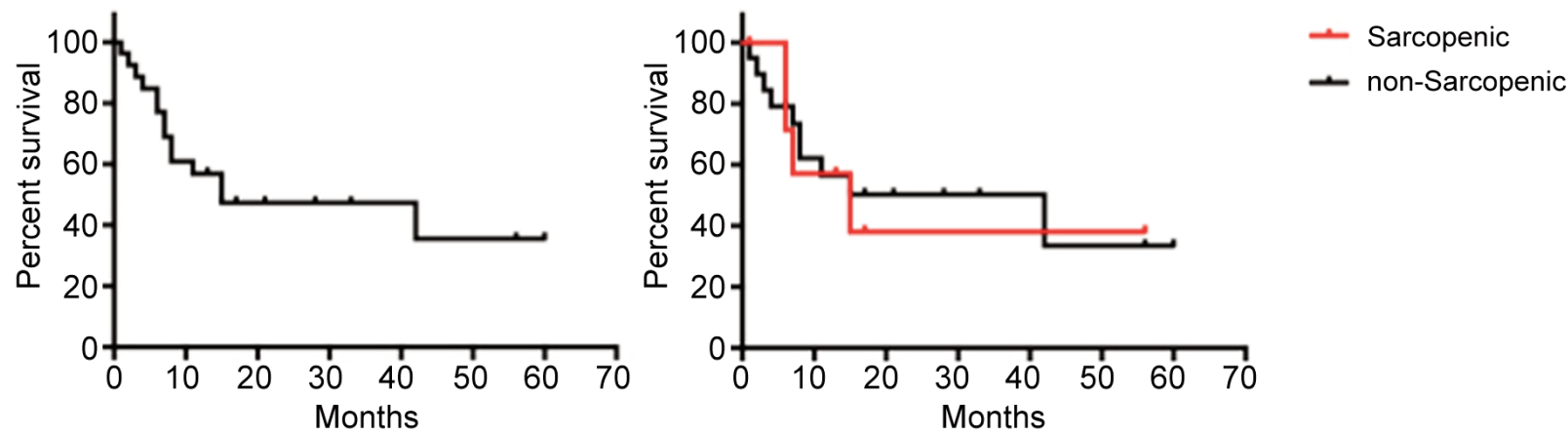

CSS

CSS
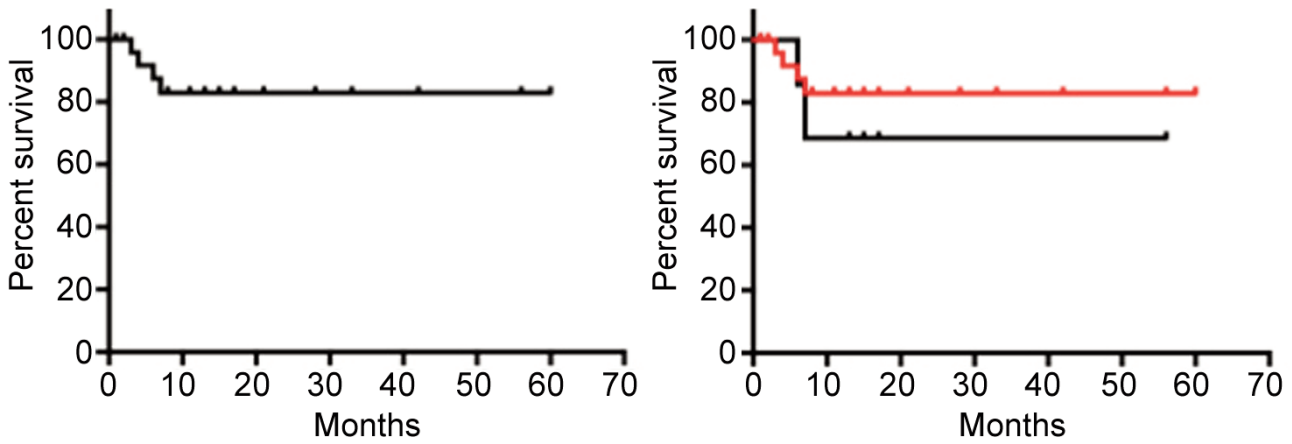

Sarcopenic
non-Sarcopenic

90-day mortality

90-day mortality
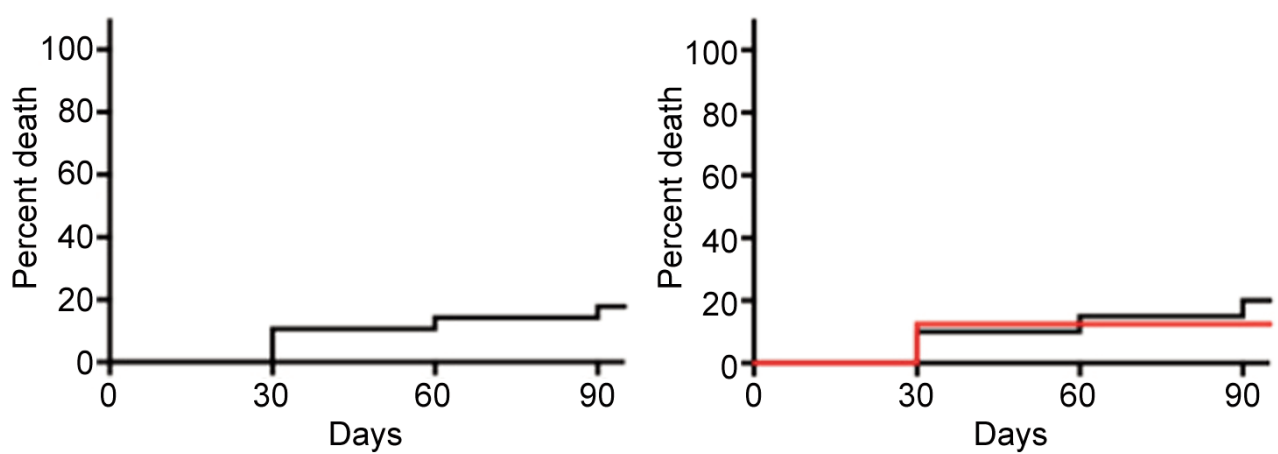

- Sarcopenic

드-Sarcopenic

Figure 2. Overall Survival, Cancer Specific Survival and 90-day mortality curves for the whole sample (left column) and comparison of the curves between sarcopenic and non-sarcopenic patients (right column).

Table II. Radiation-induced toxicity according to the RTOG scale.

\begin{tabular}{lcc}
\hline Symptoms & RTOG grade & No. of patients \\
\hline Cystitis, dysuria, strangury, haematuria, pollakiuria, anuria, incontinence, & G0/G1 & 14 \\
proctitis, diarrhea, pelvic-lumbar pain, skin erythema & G2 & 6 \\
& G3 & 6 \\
\hline
\end{tabular}


Table III. Different toxicity grades in sarcopenic and non-sarcopenic patients.

\begin{tabular}{lccc}
\hline RTOG grade goups & $\begin{array}{c}\text { No. of } \\
\text { patients }\end{array}$ & $\begin{array}{c}\text { No. of } \\
\text { sarcopenic }(\%)\end{array}$ & $\begin{array}{c}\text { No. of non- } \\
\text { sarcopenic (\%) }\end{array}$ \\
\hline $\begin{array}{l}\text { Mild-moderate (G0/G1/G2) } \\
\text { Severe (G3/G4) }\end{array}$ & 8 & $6(30)$ & $14(70)$ \\
\hline
\end{tabular}

\section{Discussion}

Sarcopenia is defined as a muscular mass loss resulting from catabolic processes activated by old age and stress factors. Surgery, radiotherapy, and chemotherapy tremendously strain the body of cancer patients, causing a greater expenditure of energy and consequently an increase in all cellular catabolic processes that, as a result, subvert tissue composition (7).

Sarcopenia is typically associated with muscular weakness, accidental falls, fractures, restriction of the daily activity and increased risk of death (23) and it provides an accurate estimate of patients' frailty thus being recently recognized as an independent predictive factor for a poor surgical outcome in elderly patients (24). The evidences that a poor muscular reserve leads to more perioperative complications, longer hospitalization and negative impact on both OS and CSS have been widely demonstrated in patients with urothelial carcinoma of the bladder submitted to radical cystectomy $(8,17,19)$, and similar results have been reported analyzing the outcomes of many other types of cancer such as breast, lung, gastric, colorectal, pancreatic, hepatobiliary carcinomas and melanoma (12-15).

In addition to an advanced stage of disease and a poor performance status, sarcopenia seems to affect not only surgery outcomes, but also chemotherapy and RT ones. In support, sarcopenic patients presenting a limited or extended small-cell lung cancer submitted to chemotherapy and/or RT showed a reduced OS (16), and those with metastatic urothelial carcinoma receiving chemotherapy developed more severe treatment-related toxicities (25). Furthermore, although not significantly affecting the OS sarcopenia was also associated to a higher frequency of acute toxicities after a stereotactic body radiation therapy for borderline resectable locally advanced pancreatic cancer (26).

Considering these results, in the present study we focused on the impact of sarcopenia on the RT outcomes of MIBC elderly patients. Despite the limited size of our sample, sarcopenic and non-sarcopenic patients responded to RT in a similar way, and no significant correlations emerged between SMI and OS, CSS, 90-day mortality and RTtoxicity. In addition, patients' comorbidities expressed according to the CCI score did not influence the OS outcomes though presenting a significant correlation with the experienced toxicity level, in agreement with the results of Santacaterina et al. and in contradiction with the studies by Mayr et al. and Boorjian et al. (4, 19, 27). Conversely, as only a small number of patients underwent chemotherapy with different regimens in terms of way of administration, time of delivery and pharmacological agents chosen, it is not possible to state how and how much its addition to RT influenced our outcomes.

We recognize that the validity of these promising results could be seriously compromised by the small size and heterogeneity of the analyzed sample; moreover, the poor life expectancy of elderly patients could hide the actual influence of both nutritional status and comorbidities on the outcomes under investigation. Another limitation is that even if the muscular status assessment of the enrolled patients was made through the accurate, reproducible and widely validated SMI method, the retrospective nature of the present study did not allow for a comparison between the SMI and other indicators of patients' frailty such as the walk test or the grip strenght test.

Nevertheless, we stress the opportunity of an active intervention on sarcopenia; indeed, the gradual understanding of the molecular and cellular basis of this potentially reversible condition is leading to the development of new therapies aimed to the restoration of muscle reserve (28).

Since the OS and CSS did not deviate from the ones reported in surgical series, RT can be safely considered a feasible treatment for sarcopenic patients unfit for surgery. Finally, it is worth to point out that the present study has an important pivotal role as it is currently the third reported study aimed to a systematic assessment of sarcopenic effects on RT's outcomes in MIBC elderly patients. Indeed, in line with our results, Stangl-Kremser et al. have highlighted how sarcopenia is not prognostic of survival in patients unfit for radical cystectomy or systemic chemotherapy (29). Furthermore in the comparison between sarcopenic $(n=67)$ and non-sarcopenic $(\mathrm{n}=79)$ patients by Fraisse et al. sarcopenia was associated with neither survival nor severity of radiation-related adverse events (30).

As stated above, the results obtained in our retrospective series can not be considered conclusive due to the small and hetereogeneous sample and the related limited power of statistical analysis. However, it indicates the efficacy and excellent tolerance of radiotherapy in the entire cohort of patients who are not candidates or who refuse surgery, regardless of their sarcopenic condition. For this reason, studies similar to this but with a necessarily greater number of patients will be carried out.

\section{Conclusion}

Sarcopenia does not seem to be a negative prognostic factor for elderly patients affected by MIBC submitted to RT. Thus, 
$\mathrm{RT}$ is a feasible and effective treatment of sarcopenic patients thanks to its low toxicity profile which makes this the best alternative to surgery. Prospective randomized studies are necessary to strenghten results' reliability and confirm this preliminary hypothesis.

\section{Conflicts of Interest}

The Authors report no conflicts of interest in relation to this study.

\section{Authors' Contributions}

GF: Conception and organization of the work; Data analysis and interpretation; Writing of the first draft; Revision of the final version of the manuscript. AC: Conception and organization of the work; Data analysis and interpretation; Writing of the first draft. SP, SL: Writing of the first draft; Literature research; Critically revised the manuscript. LM, CT, VD, IN: Data acquisition; Literature research. AP, NS, GI, AntP: Data analysis and interpretation; Literature research. SteP, AS: Conception and organization of the work; Critically revised the manuscript; Guarantor and supervisor of the study.

\section{References}

1 Associazione Italiana di Oncologia Medica AIOM: Linee guida tumori dell'urotelio, 2019. Available at: https://www.aiom.it/wpcontent/uploads/2019/10/2019_LG_AIOM_Urotelio.pdf [Last accessed on November 8, 2020]

2 Ploussard G, Shariat SF, Dragomir A, Kluth LA, Xylinas E, Masson-Lecomte A, Rieken M, Rink M, Matsumoto K, Kikuchi E, Klatte T, Boorjian SA, Lotan Y, Roghmann F, Fairey AS, Fradet $\mathrm{Y}$, Black PC, Rendon R, Izawa $\mathrm{J}$ and Kassouf W: Conditional survival after radical cystectomy for bladder cancer: evidence for a patient changing risk profile over time. Eur Urol 66: 361-370, 2014. PMID: 24139235. DOI: 10.1016/j.eururo. 2013.09 .050

3 Shariat SF, Karakiewicz PI, Palapattu GS, Amiel GE, Lotan Y, Rogers CG, Vazina A, Bastian PJ, Gupta A, Sagalowsky AI, Schoenberg $\mathrm{M}$ and Lerner SP: Nomograms provide improved accuracy for predicting survival after radical cystectomy. Clin Cancer Res 12: 6663-6676, 2006. PMID: 17121885. DOI: 10.1158/1078-0432.CCR-06-0372

4 Boorjian SA, Kim SP, Tollefson MK, Carrasco A, Cheville JC, Thompson RH, Thapa P and Frank I: Comparative performance of comorbidity indices for estimating perioperative and 5-year all cause mortality following radical cystectomy for bladder cancer. J Urol 190: 55-60, 2013. PMID: 23313198. DOI: 10.1016/j.juro.2013.01.010

5 Gregg JR, Cookson MS, Phillips S, Salem S, Chang SS, Clark PE, Davis R, Stimson CJ, Aghazadeh M, Smith JA and Barocas DA: Effect of preoperative nutritional deficiency on mortality after radical cystectomy for bladder cancer. J Urol 185: 90-96, 2011. PMID: 21074802. DOI: 10.1016/j.juro.2010.09.021

6 Roghmann F, Trinh Q-D, Braun K, von Bodman C, Brock M, Noldus $\mathrm{J}$ and Palisaar $\mathrm{J}$ : Standardized assessment of complications in a contemporary series of European patients undergoing radical cystectomy: Assessment of complications after cystectomy. Int $\mathrm{J}$ Urol 21: 143-149, 2014. PMID: 23906282. DOI: $10.1111 /$ iju.12232
7 Zargar H, Almassi N, Kovac E, Ercole C, Remer E, Rini B, Stephenson A, Garcia JA and Grivas P: Change in psoas muscle volume as a predictor of outcomes in patients treated with chemotherapy and radical cystectomy for muscle-invasive bladder cancer. Bladder Cancer 3: 57-63, 2017. PMID: 28149936. DOI: 10.3233/BLC-160080

8 Saitoh-Maeda Y, Kawahara T, Miyoshi Y, Tsutsumi S, Takamoto D, Shimokihara K, Hayashi Y, Mochizuki T, Ohtaka M, Nakamura M, Hattori Y, Teranishi J, Yumura Y, Osaka K, Ito H, Makiyama K, Nakaigawa N, Yao M and Uemura H: A low psoas muscle volume correlates with a longer hospitalization after radical cystectomy. BMC Urol 17: 87, 2017. PMID: 28923108. DOI: $10.1186 / \mathrm{s} 12894-017-0279-2$

9 Martin L, Birdsell L, MacDonald N, Reiman T, Clandinin MT, McCargar LJ, Murphy R, Ghosh S, Sawyer MB and Baracos VE: Cancer cachexia in the age of obesity: skeletal muscle depletion is a powerful prognostic factor, independent of body mass index. J Clin Oncol 31: 1539-1547, 2013. PMID: 23530101. DOI: $10.1200 / J C O .2012 .45 .2722$

10 Cruz-Jentoft AJ, Baeyens JP, Bauer JM, Boirie Y, Cederholm T, Landi F, Martin FC, Michel J-P, Rolland Y, Schneider SM, Topinkova E, Vandewoude M and Zamboni M: Sarcopenia: European consensus on definition and diagnosis: Report of the European Working Group on Sarcopenia in Older People. Age Ageing 39: 412-423, 2010. PMID: 20392703. DOI: 10.1093/ ageing/afq034

11 Fearon K, Strasser F, Anker SD, Bosaeus I, Bruera E, Fainsinger RL, Jatoi A, Loprinzi C, MacDonald N, Mantovani G, Davis M, Muscaritoli M, Ottery F, Radbruch L, Ravasco P, Walsh D, Wilcock A, Kaasa $S$ and Baracos VE: Definition and classification of cancer cachexia: an international consensus. Lancet Oncol 12: 489-495, 2011. PMID: 21296615. DOI: 10.1016/S1470-2045(10)70218-7

12 Mir O, Coriat R, Blanchet B, Durand J-P, Boudou-Rouquette P, Michels J, Ropert S, Vidal M, Pol S, Chaussade S and Goldwasser F: Sarcopenia predicts early dose-limiting toxicities and pharmacokinetics of sorafenib in patients with hepatocellular carcinoma. PLoS One 7: e37563, 2012. PMID: 22666367. DOI: 10.1371/journal.pone.0037563

13 Del Fabbro E, Parsons H, Warneke CL, Pulivarthi K, Litton JK, Dev R, Palla SL, Brewster A and Bruera E: The relationship between body composition and response to neoadjuvant chemotherapy in women with operable breast cancer. Oncologist 17: 1240-1245, 2012. PMID: 22903527. DOI: 10.1634/theoncologist.2012-0169

14 Sabel MS, Lee J, Cai S, Englesbe MJ, Holcombe S and Wang S: Sarcopenia as a prognostic factor among patients with stage III melanoma. Ann Surg Oncol 18: 3579-3585, 2011. PMID: 21822551. DOI: 10.1245/s10434-011-1976-9

15 Antoun S, Borget I and Lanoy E: Impact of sarcopenia on the prognosis and treatment toxicities in patients diagnosed with cancer: Curr Opin Support Palliat Care 7: 383-389, 2013. DOI: 10.1097/SPC.0000000000000011

16 Kim EY, Kim YS, Park I, Ahn HK, Cho EK and Jeong YM: Prognostic significance of ct-determined sarcopenia in patients with small-cell lung cancer. J Thorac Oncol 10: 1795-1799, 2015. PMID: 24189893. DOI: 10.1097/JTO.0000000000000690

17 Psutka SP, Carrasco A, Schmit GD, Moynagh MR, Boorjian SA, Frank I, Stewart SB, Thapa P, Tarrell RF, Cheville JC and Tollefson MK: Sarcopenia in patients with bladder cancer undergoing radical cystectomy: Impact on cancer-specific and 
all-cause mortality: Sarcopenia and Survival After RC for UC Cancer 120: 2910-2918, 2014. PMID: 24840856. DOI: $10.1002 /$ cncr. 28798

18 Smith AB, Deal AM, Yu H, Boyd B, Matthews J, Wallen EM, Pruthi RS, Woods ME, Muss H and Nielsen ME: Sarcopenia as a predictor of complications and survival following radical cystectomy. J Urol 191: 1714-1720, 2014. PMID: 24423437. DOI: $10.1016 /$ j.juro.2013.12.047

19 Mayr R, Gierth M, Zeman F, Reiffen M, Seeger P, Wezel F, Pycha A, Comploj E, Bonatti M, Ritter M, van Rhijn BWG, Burger M, Bolenz C, Fritsche H-M and Martini T: Sarcopenia as a comorbidity-independent predictor of survival following radical cystectomy for bladder cancer: Sarcopenia and radical cystectomy. J Cachexia Sarcopenia Muscle 9: 505-513, 2018. PMID: 29479839. DOI: 10.1002/jcsm.12279

20 Cacciola A, Parisi S, Tamburella C, Lillo S, Ferini G, Molino L, Iatì G, Pontoriero A, Bottari A, Mazziotti S, Cicero G, Minutoli F, Blandino A and Pergolizzi S: Stereotactic body radiation therapy and radiofrequency ablation for the treatment of liver metastases: How and when? Rep Pract Oncol Radiother 25: 299306, 2020. PMID: 32194349. DOI: 10.1016/j.rpor.2020.02.010

21 Iatì G, Parisi S, Santacaterina A, Pontoriero A, Cacciola A, Brogna A, Platania A, Palazzolo C, Cambareri D, Davì V, Napoli I, Lillo S, Severo C, Tamburella C, Vadalà R, Delia P and Pergolizzi S: Simultaneous integrated boost radiotherapy in unresectable stage IV (M0) head and neck squamous cell cancer patients: Daily clinical practice. Rep Pract Oncol Radiother 25: 399-404, 2020. PMID: 32368191. DOI: 10.1016/j.rpor.2020.04.006

22 Pontoriero A, Iatì G, Cacciola A, Conti A, Brogna A, Siragusa C, Ferini G, Davì V, Tamburella C, Molino L, Cambareri D, Severo C, Parisi S, Settineri N, Ielo I and Pergolizzi S: Stereotactic body radiation therapy with simultaneous integrated boost in patients with spinal metastases. Technol Cancer Res Treat 19: 153303382090444, 2020. PMID: 32336255. DOI: $10.1177 / 1533033820904447$

23 Shaw SC, Dennison EM and Cooper C: Epidemiology of Sarcopenia: Determinants Throughout the Lifecourse. Calcif Tissue Int 101: 229-247, 2017. PMID: 28421264. DOI: 10.1007/s00223-017-0277-0

24 Makary MA, Segev DL, Pronovost PJ, Syin D, Bandeen-Roche K, Patel P, Takenaga R, Devgan L, Holzmueller CG, Tian J and Fried LP: Frailty as a predictor of surgical outcomes in older patients. J Am Coll Surg 210: 901-908, 2010. PMID: 20510798. DOI: $10.1016 /$ j.jamcollsurg.2010.01.028
25 Taguchi S, Akamatsu N, Nakagawa T, Gonoi W, Kanatani A, Miyazaki H, Fujimura T, Fukuhara H, Kume H and Homma Y: Sarcopenia evaluated using the skeletal muscle index is a significant prognostic factor for metastatic urothelial carcinoma. Clin Genitourin Cancer 14: 237-243, 2016. PMID: 26337653. DOI: $10.1016 /$ j.clgc.2015.07.015

26 Jin WH, Mellon EA, Frakes JM, Murimwa GZ, Hodul PJ, Pimiento JM, Malafa MP and Hoffe SE: Impact of sarcopenia in borderline resectable and locally advanced pancreatic cancer patients receiving stereotactic body radiation therapy. J Gastrointest Oncol 9: 24-34, 2018. PMID: 29564168. DOI: 10.21037/jgo.2017.09.13

27 Santacaterina A, Platania A, Palazzolo C, Spatola C, Acquaviva G, Crispi M, Privitera G, Settineri N and Pergolizzi S: Very elderly (>80 years), frail patients with muscle-invasive bladder cancer and comorbidities: is curative irradiation feasible? Tumori J 101: 609-613, 2015. PMID: 25983093. DOI: 10.5301/tj.5000361

28 Sayer AA, Robinson SM, Patel HP, Shavlakadze T, Cooper C and Grounds MD: New horizons in the pathogenesis, diagnosis and management of sarcopenia. Age Ageing 42: 145-150, 2013. PMID: 23315797. DOI: 10.1093/ageing/afs 191

29 Stangl-Kremser J, D'Andrea D, Vartolomei M, Abufaraj M, Goldner G, Baltzer P, Shariat SF and Tamandl D: Prognostic value of nutritional indices and body composition parameters including sarcopenia in patients treated with radiotherapy for urothelial carcinoma of the bladder. Urol Oncol Semin Orig Investig 37: 372-379, 2019. PMID: 30578161. DOI: 10.1016/j.urolonc.2018.11.001

30 Fraisse G, Renard Y, Lebacle C, Masson-Lecomte A, Desgrandchamps F, Hennequin C, Bessede T and Irani J: La sarcopénie est-elle un facteur de morbi-mortalité dans le traitement des tumeurs localisées de la vessie infiltrant le muscle ? Prog En Urol 30: 41-50, 2020. PMID: 31818689. DOI: $10.1016 /$ j.purol.2019.11.002
Received October 18, 2020

Revised November 7, 2020

Accepted November 8, 2020 